\title{
Commentary reporting guide
}

Correspondence: ccdr-rmtc@phac-aspc.gc.ca

Commentaries are opinion papers that are designed to stimulate thinking and debate. They identify an issue, place it in a larger context and then offer some insights to educate, motivate or formulate an opinion. They are typically 1,000-1,500 words in length and have 10-15 references.

Commentaries have an engaging title and a text abstract of 150- 200 words.

The introduction is typically two to four paragraphs that identify an issue and state why it is important. The introduction articulates a position and outlines the key arguments to support that position.

The body of the commentary is five to eight paragraphs and provides an analysis of the issue. A paragraph or two can be provided to develop each of the arguments and consider strengths, weaknesses (or counter-arguments) as well as policy and practice implications. Assertions are supported with key references. Examples may be used to illustrate or support a point. A table summarizing key information may be useful.

The conclusion is one or two paragraphs. It highlights the key message of the commentary and provides recommendations for moving forward or next steps.

As with all submissions, check CCDR's Information for authors (published in January every year with the first issue of each new volume) for general aspects of manuscript preparation and submission requirements. 